\title{
ATUAÇÃO DO BIBLIOTECÁRIO JUNTO A POPULAÇÃO EM SITUAÇÃO DE RUA
}

\author{
THE LIBRARIAN'S ACTIVITIES TOWARD THE \\ HOMELESS POPULATION
}

\author{
Shirlei Rossato Pelarin Gonçalves ${ }^{1}$ \\ Luciana de Souza Gracioso² \\ Carla Regina Silva ${ }^{3}$
}

\begin{abstract}
RESUMO
Introdução: Muitos direitos são renegados as pessoas que vivem em situação de rua no Brasil, dentre eles, o direito de acesso ao livro e a leitura. Objetivo: Foi objetivo desta pesquisa discutir o lugar do Bibliotecário enquanto promotor e participante de ações de promoção e acesso ao livro e a leitura para pessoas nesta situação. Metodologia: Trata-se de pesquisa exploratória, com base em pesquisa bibliográfica e documental e observação participante em projeto de extensão intitulado "Memória falada" desenvolvido pela Universidade Federal de São Carlos, junto a Casa de Passagem do município de São Carlos. Resultados: Os resultados apontam para a necessidade de uma formação mais crítica a ser ofertada ao profissional bibliotecário de modo que o mesmo possa se sensibilizar e atuar politicamente com questões que envolvem a sociedade. Conclusão: Demonstra como é possível, na prática, que o Bibliotecário atue junto a setores públicos para o desenvolvimento de projetos sociais.
\end{abstract}

Descritores: Bibliotecário. População em Situação de Rua. Sociedade.

\footnotetext{
${ }^{1}$ Bacharel em biblioteconomía pela Universidade Federal de São Carlos (UFSCar). E-mail: shirleirossato@gmail.com

2 Professora do Departamento de Ciência da Informação da Universidade Federal de São Carlos (UFSCar). E-mail: luciana@ufscar.br

${ }^{3}$ Professora do Departamento de Terapia Ocupacional da Universidade Federal de São Carlos (UFSCar). E-mail: carlametuia@gmail.com
} 


\section{INTRODUÇÃO}

Segundo a Constituição Federal Brasileira de 1988, toda pessoa tem direito a educação sem distinção de raça, cor, sexo, religião. Da mesma forma todos tem direito à informação e a leitura. Como o direito à educação é previsto por lei, o direito à leitura também o é. Os Ministérios da Cultura e da Educação criaram o Plano Nacional de Livro e Leitura em 2006 (MARQUES NETO, 2006), cujas diretrizes principais são: democratização do acesso ao livro; fomento à leitura; formação de mediadores; valorização institucional da leitura e incremento de seu valor simbólico; e desenvolvimento da economia do livro.

No Brasil, as diferenças sociais estão presentes e aumentam a cada dia, com isso, os que não dominam a arte de ler, os que não conseguem se qualificar, como os mais desfavorecidos financeiramente ficam excluídos de qualquer oportunidade mais qualificada de inserção no mercado de trabalho. Neste perfil se enquadram boa parte das pessoas que vivem em situação de rua no Brasil.

Esse extrato da população é erroneamente conhecido como: mendigo; morador de rua, mas o Decreto № 7.053 de 23 de dezembro de 2009 que institui a Política Nacional para a População em Situação de Rua e o Comitê Intersetorial de Acompanhamento e Monitoramento, em seu artigo $1^{\circ}$ caracteriza esses indivíduos como população em situação de rua e atribuem as seguintes características: Grupo populacional heterogêneo que possui em comum a pobreza extrema, os vínculos familiares interrompidos ou fragilizados e a inexistência de moradia convencional regular, e que utiliza os logradouros públicos e as áreas degradadas como espaço de moradia e de sustento, de forma temporária ou permanente, bem como as unidades de acolhimento para pernoite temporário ou como moradia provisória. Segundo o Art. $5^{\circ}$ deste decreto, além da igualdade e da equidade, é proposto: "I - respeito à dignidade da pessoa humana; II - direito à convivência familiar e comunitária; III valorização e respeito à vida e à cidadania; IV - atendimento humanizado e universalizado." 
Pesa sobre essa população o preconceito de toda uma sociedade. $O$ fato de andarem sujos faz com que geralmente sejam proibidos de usar recintos públicos como restaurantes, comércio, banheiros, praças públicas. São consideradas pessoas sem identidade. As ruas os tornam vulneráveis, ficam sujeitos a qualquer situação de violência. Ficam sujeitos a muitas doenças, pois não tem acesso à água potável, comida saudável e não tem lugares adequados para dormir, assim, eles têm poucas horas de sono, ficam privados de banho, e também muitos perdem seus documentos, o que para eles é um fator de dificuldade para conseguir outra documentação a falta de endereço fixo, agravando a possibilidade de conseguirem um emprego ou mesmo um atendimento médico, ou uma vaga em uma escola. Com isso sua autoestima vai diminuindo, portanto, é necessária a criação de políticas públicas adequadas e eficazes a essa população.

As diretrizes e os objetivos da Política Nacional para População em Situação de Rua propõem a igualdade e a equidade, respeito e garantia dos direitos as condições sociais e culturais de uma população tão heterogênea, que tenha um serviço humanizado, e pressupõe uma série de serviços como moradia temporária, bem como, direito a saúde, trabalho, assistência social, cultura, esporte, lazer e educação.

O que vemos é a atuação de Organizações Não Governamentais (ONGs) e de Instituições Religiosas que tem fundo assistencial e, mas que não são suficientes para atender completamente as necessidades dessa população. Outros órgãos que atuam e que deveriam dar todo suporte a essa população seriam os abrigos temporários e os albergues, mas que são insuficientes para suprir as necessidades e a demanda dessa população.

Frente ao cenário exposto, temos como premissa que o Bibliotecário tem um compromisso profissional e social, que extrapola os muros da Biblioteca. Enfim, o papel do bibliotecário vai além de conhecer técnicas e meios que auxiliem na localização da informação: ele também precisa ser um agente social, empreendedor e disseminador do conhecimento e da cultura que estão guardados nos acervos, envolvendo e estimulando os potenciais usuários a desenvolver o hábito de ler e de frequentar bibliotecas regularmente, ou ainda, 
o bibliotecário pode também assumir o lugar da busca ativa e ir ao encontro de seu usuário.

Neste sentido, foi objetivo desta pesquisa discutir o lugar do Bibliotecário enquanto promotor e participante de ações de promoção e acesso ao livro e a leitura para pessoas nesta situação. Com isso elencou-se como objetivo específico descrever e analisar o papel do Bibliotecário como mediador da leitura e as dinâmicas de funcionamento da mediação da informação entre o setor público e a População em Situação de Rua no que diz respeito aos seus direitos, deveres e acesso a informação.

Para atingir o objetivo proposto esta pesquisa foi exploratória, com base em pesquisa documental em sites institucionais e documentos legais e foi feita pesquisa bibliográfica com o objetivo de identificar o conhecimento disponível sobre o assunto, como fontes de pesquisa em artigos, livros, periódicos, e outros trabalhos científicos. Além disso, também foi desenvolvida uma observação participante junto às reuniões desenvolvidas no âmbito municipal da cidade de São Carlos, no interior do Estado de São Paulo, sobre os direitos que a população de rua é baseada. Para análise de resultados foi feita uma análise de conteúdo dos materiais identificados e pesquisados procurando responder aos objetivos propostos.

O trabalho proposto serviu de respaldo ao Projeto de Extensão "Memória Falada: a história da população em situação de rua como patrimônio imaterial de cultura'", desenvolvido na Universidade Federal de São Carlos (UFSCar), coordenado pela Profa. Dra. Carla Regina Silva, desenvolvido na Casa de Passagem Saber Amar, no município de São Carlos, São Paulo, localizado na Rua Rotary Club, 101. A Casa de Passagem segundo seu regimento interno tem como objetivo: atender pessoas que se encontram em situação de rua ou necessitando de atendimento social e de saúde, através da rede de assistência

\footnotetext{
${ }^{1}$ O projeto de extensão "Memória Falada" foi fruto de pesquisa e extensão desenvolvido de modo transdisciplinar entre cursos de Terapia Ocupacional (TO) e Biblioteconomia e Ciência da Informação (BCl) da Universidade Federal de São Carlos (UFSCar), via participação do PET $\mathrm{BCl}$ (Programa de Educação Tutorial). Neste projeto houve toda uma articulação com serviços socioassistenciais do município de São Carlos e população em situação de rua. O projeto teve início em 2015 e foi finalizado em 2017. A síntese das atividades desenvolvidas no projeto foram descritas por SILVA et al, 2017.
} 
social, resgatando a autoestima, garantindo direito à cidadania, reintegração à família e inclusão social.

Outras ações que são desenvolvidas no bojo do Programa de Extensão é a participação do Fórum de Moradores de Rua de São Carlos, no sentido de dizer que o morador em situação de rua de posse de conhecimento e informação leva ao conhecimento de seus direitos podendo criar associações para reivindicar melhorias para sua sobrevivência como: habitação, trabalho, cursos profissionalizantes, escolas, saúde, tratamento, e condições para sair dessa situação tão vulnerável e sair do anonimato.

Estes dois espaços: Casa de Passagem e Fórum de Moradores de Rua de São Carlos foram os campos em que foi desenvolvida a observação participante e serviram de inspiração para a discussão do papel do bibliotecário como mediador da informação sobre políticas públicas e agente social.

\section{DIREITOS HUMANOS: DO DIREITO À IGUALDADE SOCIAL AO DIREITO À LEITURA}

Os direitos humanos preconizam a igualdade entre todas as pessoas, porque é um direito de todo ser humano, todos têm direito à liberdade, a igualdade, sem discriminação de raça, sexo, religião, os direitos humanos repudiam a intolerância, a injustiça, a opressão e a escravidão.

Após duas guerras que disseminaram tanta morte, em 1945 vários países se reuniram e formaram a Organização das Nações Unidas (ONU), onde formularam diretrizes e conceitos preconizando a paz mundial, e declarando esses direitos. Esse documento tem 30 direitos redigidos, desde 0 direito a ser livre e se expressar, direito a vida, a não discriminação, a não escravidão, a moradia, a comida, a diversão, ao trabalho, a educação, e outros.

Até hoje, em muitos países, cidades e comunidades, essa luta permanece, ainda hoje há milhões de pessoas discriminadas e privadas desse direito. Os direitos começam no nosso círculo como: a vizinhança, o seu trabalho, a escola, a universidade, a comunidade na qual está inserido, a sua cidade. As pessoas têm que ter seus direitos garantidos pelos órgãos públicos. 
A Organização das Nações Unidas criou um órgão executivo e exclusivo para tratar as questões voltadas para a Educação, a Ciência e a Cultura, que é a UNESCO. Ela atua nas áreas da Educação, Ciências Naturais, Ciências Humanas e Sociais, Cultura e Comunicação e Informação.

A UNESCO desenvolve parcerias com os governos dos países, estados e municípios, bem como, com a sociedade civil e a iniciativa privada, participa na formulação de políticas públicas entre os Estados membros da Organização com o intuito de reduzir o analfabetismo no mundo, financiando programas para a formação de professores. Atua na promoção de pesquisas para a exploração de recursos naturais, bem como, na proteção e restauração dos patrimônios históricos da humanidade. Também atua na conservação do meio ambiente, na disseminação do conhecimento, na liberdade de expressão, e de imprensa.

Portanto, fomenta que políticas públicas devam ser implantadas para dar solução, ou diminuir a desigualdade social, dando a todos a oportunidade a educação, a informação, e a leitura, inclusive a população em situação de rua, pois os direitos são universais e consequentemente assegurados a todos.

A agenda 2030 das Nações Unidas, lançada em 2015, tem 17 Objetivos de Desenvolvimento Sustentável (ODS) e 169 Metas (econômicas, ambientais e sociais) centradas nas Pessoas, na Prosperidade, na Paz, nas Parcerias e no Planeta. A International Federation of Library Associations and Institutions (IFLA) entra neste processo e coloca as Bibliotecas como equipamento indispensável para a Sociedade na promoção da equidade social. No Brasil, a Federação Brasileira de Associações de Bibliotecários (FEBAB) entra nesta parceria para envolver as Bibliotecas Brasileiras neste movimento global e publica As bibliotecas e a implementação da Agenda 2030 da ONU ferramentas e também Acesso e oportunidade para todos: como as bibliotecas contribuem para a agenda 2030 das Nações Unidas. Os objetivos da Agenda 2030 são:

1- Erradicar a pobreza;

2- Acabar com a fome;

3- Vida saudável;

4- Educação de qualidade; 
5- Igualdade de gênero;

6- Água e saneamento;

7- Energias renováveis;

8- Trabalho digno e crescimento econômico;

9- Inovação e infraestruturas;

10- Reduzir as desigualdades;

11- Cidades e comunidades sustentáveis;

12- Produção e consumo sustentáveis;

13- Combater as alterações climáticas;

14-Oceanos, mares e recursos marinhos;

15-Ecossistemas terrestres e biodiversidade;

16-Paz e justiça;

17-Parcerias para o desenvolvimento.

Frente ao exposto e considerando o envolvimento já anunciado pela IFLA em âmbito internacional e pela FEBAB no cenário nacional, fica evidente que Bibliotecário e Biblioteca tem lugar estratégico e determinante no cumprimento desta agenda de desenvolvimento social. Neste trabalho, o que descrevemos é o relato de um movimento feito neste sentido, junto as pessoas em situação de rua.

\section{PESSOAS EM SITUAÇÃO DE RUA: UM OLHAR SOBRE A CIDADE DE SÃO CARLOS, SP}

Em 2005 foi realizado e organizado pelo Ministério do Desenvolvimento Social e Combate à Fome através da Secretaria Nacional de Assistência Social o primeiro Encontro Nacional sobre População em Situação de Rua, onde ficou definido como um grupo populacional heterogêneo, composto por pessoas com diferentes realidades, mas que têm em comum a condição de pobreza absoluta, vínculos interrompidos ou fragilizados e falta de habitação convencional regular, sendo compelido a utilizar a rua como espaço de moradia e sustento, por contingência temporária ou de forma permanente. 
A partir desse encontro foram levantados os desafios e as estratégias que deveriam seguir para a construção de uma política pública, abrangendo a garantia dos direitos à assistência social, saúde, educação, habitação, cultura, geração de empregos, voltada para essa população, onde abrangeria todas as instâncias governamentais federais, estaduais e municipais, bem como, as secretarias. Seriam traçadas atitudes para combater o preconceito e garantir os direitos previstos na constituição e órgãos internacionais como a UNESCO.

Entre 2007 e 2008, o Ministério do Desenvolvimento Social e Combate a Fome realizou uma pesquisa nacional censitária nas cidades com mais de 300 mil habitantes, exceto nas capitais: Belo Horizonte, São Paulo, Recife e Porto Alegre, sendo assim investigadas 71 cidades.

A pesquisa identificou 31.922 pessoas maiores de 18 anos vivendo nas ruas, pressupondo que esse número seja muito maior que isso, dado que algumas cidades não foram incluídas na pesquisa.

Nessa pesquisa segundo a Política Nacional para Inclusão Social da População em Situação de Rua (Brasília/DF, maio/2008), essa população é constituída na maioria por homens (82\%), entre 25 e 44 anos, sendo que dos entrevistados $74 \%$ sabem ler e escrever; $17,1 \%$ não sabem escrever e $8,3 \%$ apenas assinam o nome; $95 \%$ não estão estudando atualmente e que somente $3,8 \%$ declararam estar fazendo algum curso de ensino formal ou profissionalizante. Verificou-se que $48,4 \%$ não concluíram o primeiro grau e 17,8\% não souberam responder/não lembram o seu nível de escolaridade, sendo que apenas 3,2\% concluíram o segundo grau. (BRASIL, 2008)

O Decreto Presidencial no 7053 de 23 de dezembro de 2009 que institui a Política Nacional para a população em situação de rua e o Comitê Intersetorial de Acompanhamento e Monitoramento, juntamente com esses dados estatísticos, promulga os princípios, diretrizes e objetivos, envolvendo todas as instâncias governamentais e a sociedade civil a desenvolver e executar projetos que visam beneficiar essa população. O Decreto prevê no artigo $5^{\circ}$ além do princípio da igualdade e equidade, o respeito à dignidade e 0 direito ao atendimento humanizado e universalizado.

$\mathrm{Na}$ cidade de São Carlos, os equipamentos que atendem essa população são o Centro de Referência Especializado em Atendimento à 
População em Situação de Rua (Centro POP) que é um espaço para convivência grupal, social e para o desenvolvimento de relações de solidariedade, afetividade e respeito, para estimular a autonomia. Para muitos 0 Centro POP serve de referência como endereço. Atualmente esse dispositivo não conta com nenhuma oficina profissionalizante, tendo administração direta da Prefeitura Municipal. O município conta ainda com o atendimento do Albergue Noturno que foi fundado na década de 1960, mas a partir de 2015 funciona como Casa de Passagem. Atualmente esse serviço é terceirizado com financiamento da prefeitura. Trata-se de uma instituição sem fins lucrativos.

\section{O PAPEL MEDIADOR DO BIBLIOTECÁRIO NO CONTEXTO SOCIAL}

Informação é um direito de todos, como prevê a Constituição, e os Direitos Humanos através de órgãos como a UNESCO. A informação leva à cidadania. É através dela que o indivíduo passa conhecer seus direitos e deveres, e a compreender o contexto em que vive, com autonomia para analisar as situações e apto a tomar decisões. O bibliotecário deve fazer essa ponte entre a informação/usuário, tornando-a de fácil entendimento.

Nesse contexto, verificamos que com a globalização surgem novas informações a todo o momento e são lançadas na mídia. O desenvolvimento de novas tecnologias gera ao mesmo tempo muito conhecimento, mas ao mesmo tempo distancia aqueles que são menos favorecidos, gerando uma desagregação maior entre as classes. Vivemos num mundo competitivo, onde, a informação e conhecimento são sinônimos de poder, gerando desigualdades para aqueles que não têm oportunidades de se qualificar ou adquirir tais conhecimentos. A falta de atitudes e políticas públicas por parte dos governos, que deveria proporcionar escolas, material didático, e capacitação profissional para os educadores, bibliotecas públicas e escolares com acervos atualizados, fica por responsabilidade do bibliotecário/educador ser um mediador da leitura, informação, conhecimento e trazer ao seu usuário competências para entender essas novas tecnologias e disseminar informações tão complexas para a realidade desse usuário. 
O bibliotecário, como mediador de leitura/informação deve estar em contínua aprendizagem, melhorando suas qualificações e competências, participando e colaborando com a crescente demanda de informação nos diversos segmentos da sociedade, a exemplo a escola, a biblioteca pública, os asilos, os orfanatos, o usuário, as comunidades carentes, as populações menos favorecidas como moradores em situação de rua.

O profissional tem também a função de agente socializador da informação, podendo contribuir nesse processo de aprendizagem por meio de diversas formas de leituras e suporte, como também em suas práticas, ajudando o leitor a atingir um nível elevado de complexidade no processo leitura/escrita, e na produção de cidadania, atuando de forma interdisciplinar com educadores, psicólogos, sociólogos, terapeutas ocupacionais para emancipar esse usuário.

Neste contexto, o bibliotecário deve adquirir habilidades que estão além do tratamento da informação tecnológica e cientifica. Ele deve ter o entendimento de questões e tendências globais e valorizar os direitos humanos, a diversidade, a justiça, a democracia e não a discriminação e a intolerância, o profissional deve saber trabalhar em equipe, ser criativo, ser participativo e conhecer o contexto dos seus usuários.

Temos três personagens fundamentais no processo de leitura - $\mathrm{o}$ autor, o leitor e o mediador. O mediador ganha papel importante proporcionalmente à imaturidade do leitor, ou seja, "[...] quanto mais imaturo o leitor, mais precisará de um outro 'personagem' no processo de leitura, que denominamos de mediador de leitura." (ALMEIDA JÚNIOR; BORTOLIN, 2007, p. 03). Este mediador é aquele que levará o leitor ao interesse e conhecimento pelo "saber" e com a sua colaboração ética, além de despertar o desejo à leitura, terá a possibilidade de contribuir com o ensinamento de atitudes corretas.

$O$ autor defende a mediação da informação ao contrário da disseminação da informação. A disseminação da informação seria apenas a disponibilização da informação pelo bibliotecário enquanto que a mediação não estaria restrita apenas à disponibilização, mas em todas as ações do profissional da informação, como a seleção, processamento técnico, desenvolvimento de coleções, entre outros citados no texto, como explica 
Almeida Júnior e Bortolin, (2007, p. 07) "[...] Especificamente, em relação à área de Ciência da Informação, o seu objeto passaria a ser mais a mediação do que a informação."

Assim, haverá interferência do profissional da informação nas ações efetuadas, elas não serão neutras ou imparciais, porém há de se atentar que as ações jamais deverão ser manipuladoras.

O profissional da informação, assim, passa a ser entendido em uma outra esfera, em um outro estrato profissional, o daqueles que fazem história, são sujeitos na sociedade e participam efetivamente da construção do destino da humanidade (ALMEIDA JÚNIOR, BORTOLIN, 2007, p. 08).

Essa afirmação justifica nossa defesa de que o bibliotecário deve sair da posição passiva em direção a uma posição ativa em relação ao leitor, aproximando-se do mesmo e trocando experiências com ele. Para atender este requisito, o bibliotecário precisará ser um profissional que se disponha a buscar - conhecimento nas mais diversas áreas para assim satisfazer as necessidades dos usuários.

No texto de Santos, Santos e Assunção (2014) fica claro que a construção de uma sociedade justa está diretamente ligada ao acesso à informação, pois o cidadão que conhece seus direitos e deveres possui argumentos para suas reinvindicações, ou seja, possui argumentos para o exercício de sua cidadania. É neste contexto que o papel do bibliotecário ganha grande importância, pois é ele quem tornará o acesso à informação disponível a todos os níveis de usuários de forma ética.

A informação é o instrumento de poder e transformação, por isso o profissional da informação deve viabilizar o acesso à informação contribuindo para a melhoria da sociedade. [...] bibliotecários aparentemente teriam que assumir a consciência de que o direito à cidadania é um direito também à construção do próprio discurso. Assim, o direito que nos assegura ter conhecimentos a leis e deveres, é o mesmo direito que nos faz entender a prática da cidadania enquanto mediadores de trocas de informação. (SANTOS; SANTOS; ASSUNÇÃO, 2014, p. 05). 
Com isso, mostra-se a importância social do bibliotecário em como e onde disponibilizar e disseminar a informação, orientando quais ferramentas de busca poderá ser utilizada, pautado na ética.

Como profissional da informação, sua ação deve ser pautada em valores democráticos, solidários e de responsabilidade em relação ao planeta, considerando também o enraizamento de sua identidade nacional. [...] O bibliotecário é agente importante nesse contexto informacional, pois é o facilitador para o acesso adequado a essa informação, que pode ser adquirida através da leitura das fontes formais. (SANTOS; SANTOS; ASSUNÇÃO, 2014, p. 05-06)

Em um país onde ainda temos alto índice de analfabetismo, aumenta-se a responsabilidade do bibliotecário, não somente na forma como fazer chegar a informação a esta faixa da sociedade e demais faixas, como também na busca de métodos e participação na interação com os usuários, incentivando o conhecimento, ajudando na formação do cidadão.

Mesmo assim ainda há o problema de que a Biblioteca, eventualmente, pode ser vista como um lugar onde somente pessoas que sabem ler e escrever possam frequentar, pessoas que sabem o que vão buscar com relação a informação e conhecimento. Cabe ao bibliotecário desmistificar essa visão errônea, provendo a população do conhecimento de que a biblioteca é de livre acesso à todos que necessitam de informação, cultura, lazer. Ao mesmo tempo, também cabe a ele ir ao encontro do usuário, deste leitor potencial que esta em situação de rua. A rua, neste sentido, também se torna um lugar de atuação profissional.

\section{APRESENTAÇÃO E DISCUSSÃo dOS RESULTADOS ALCANÇADOS DURANTE A OBSERVAÇÃO PARTICIPANTE}

Com o objetivo inicial de identificar e sensibilizar os "trecheiros" que passavam pela Casa de Passagem em São Carlos para as entrevistas e para promoção das atividades de Leitura foram planejadas e desenvolvidas uma sequência de ações no bojo do Projeto Memória Falada. Assim, em 2016, durante as segundas-feiras, no período da tarde, foram realizados encontros 
com a população em situação de rua que circulam na Casa de Passagem e a população trecheira que utiliza os serviços fornecidos pela instituição. Nestas ocasiões foram desenvolvidas atividades de sensibilização e foram gravadas entrevistas com aqueles que se interessavam e aceitavam registrar suas memórias. O projeto também expandiu sua atuação para as praças do município, com o intuito de tecer as histórias com o máximo de indivíduos possíveis. Essas memórias foram coletadas e registradas em vídeo e depois disponibilizadas em site específico. As ações de sensibilização e desenvolvimento das entrevistas ficaram por conta dos alunos e da docente do curso de Terapia Ocupacional da UFSCar. A elaboração do site e organização e sistematizações dos produtos documentários ficaram por conta do Grupo $\mathrm{PET} / \mathrm{BCl}$ (Programa de Educação Tutorial de Biblioteconomia e Ciência da Informação). Todas as entrevistas disponibilizadas foram consentidas e termos de uso de imagem foram assinados pelos participantes, no bojo do projeto de extensão da UFSCar. $O$ site que reúne estas memórias é: https://memoriafalada.wordpress.com/ $/^{2}$. A interface de entrada do site pode ser conferida na imagem a seguir:

\footnotetext{
${ }^{2}$ Segundo Silva et al. (2017) "No que diz respeito ao tratamento do material coletado, destacase 0 arquivamento em nuvem das fotografias, áudios e vídeos produzidos, em plataforma colaborativa. Estes documentos receberam tratamento temático e descritivo, e passaram por uma política de seleção para avaliação dos conteúdos que foram disponibilizados no site do 'museu virtual da pessoa em situação de rua'. Esta interface esta sendo modelada em Wordpress inicialmente, mas respeitando-se critérios de navegabilidade, acessibilidade e usabilidade do sistema. Taxonomias específicas estão sendo estudadas para estruturar a interface de modo que as memórias sejam evidenciadas e descritas adequadamente no museu. $O$ intuito desta plataforma e ampliar o alcance e as possibilidades de visibilidade sobre as histórias de vida da população em situação de rua, que possam subsidiar a reflexão para configuração e ajustes de políticas voltadas a este público."
} 
Imagem 1: Interface do Blog Memória Falada

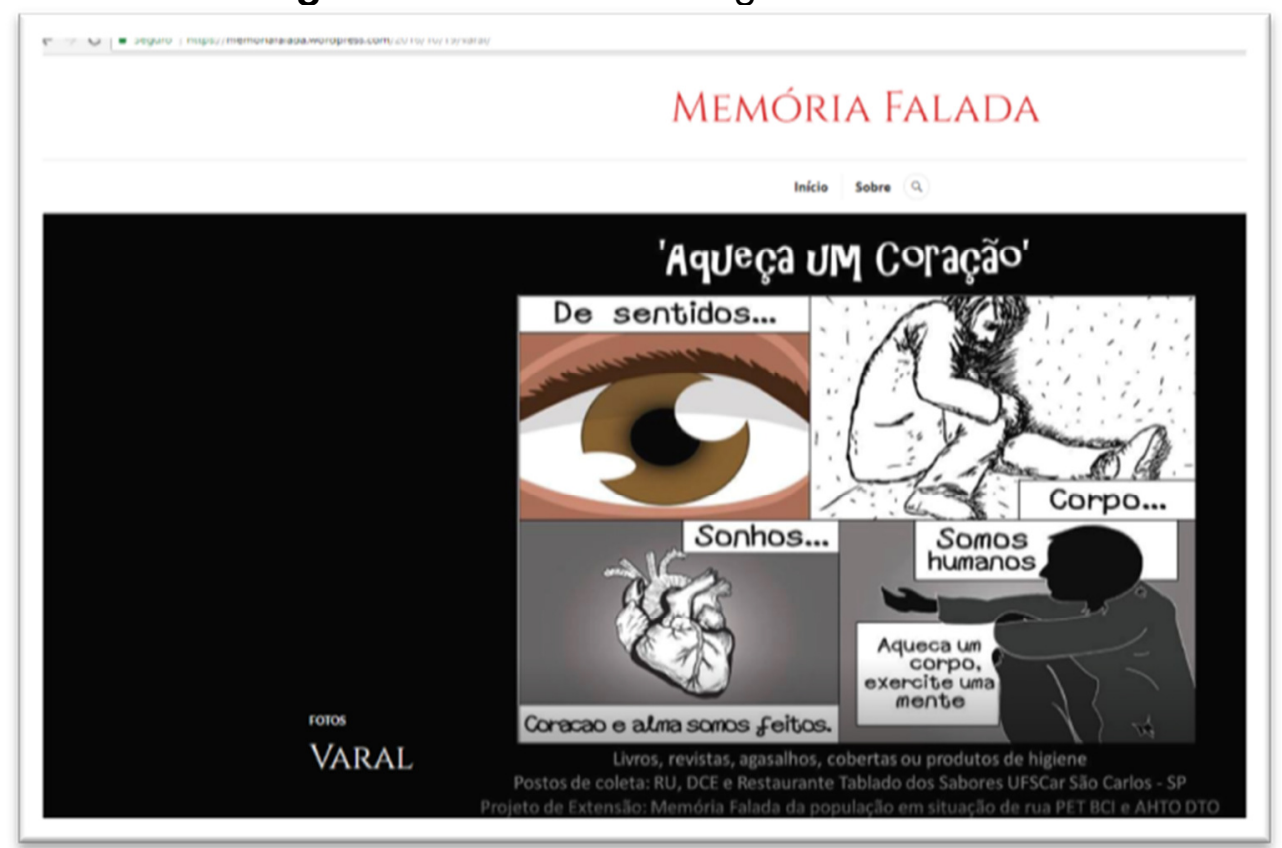

Fonte: (MEMÓRIA FALADA, 2016)

A apresentação completa do Site memória falada pode ser conferida em: <https://www.youtube.com/watch?v=LMcDrL1tELI\&feature=youtu.be $>$.

Imagem 2: Interface da apresentação do Blog Memória Falada no YouTube.

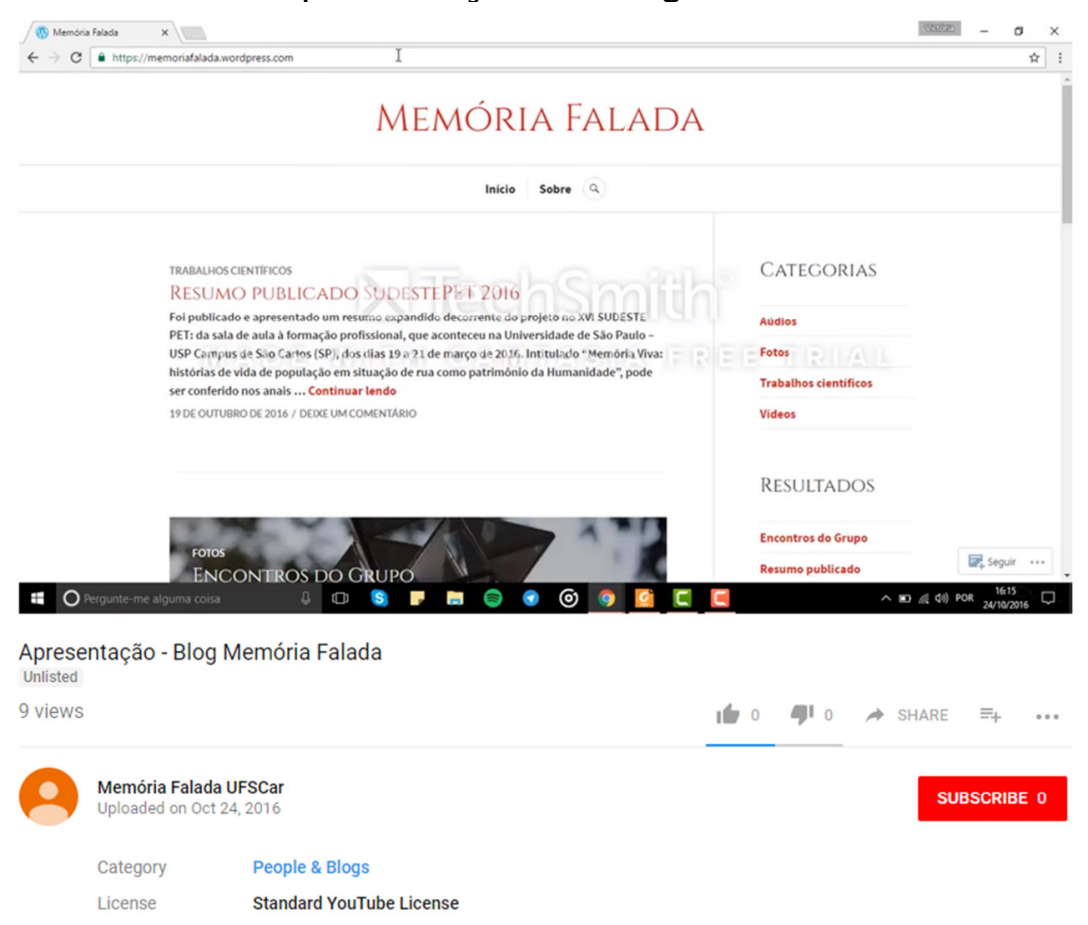

Fonte: (MEMÓRIA FALADA UFSCar, 2016) 
As principais atividades desenvolvidas junto aos trecheiros, durante suas passagens na Casa de Passagem foram: Linha da vida; Minha vida da um livro; Jogo da memória; e a "geladeiroteca" (promovida pelo Grupo PET/BCl em parceria).

Dentre estas atividades destacamos duas emq eu o papel do Bibliotecário foi decisivo: a Geladeiroteca e a participação junto ao Fórum de Pessoas em Situação de Rua. A "geladeiroteca", que foi instalada adquirida por doação, pintada e levada a Casa de Passagem pelo Grupo PET/BCl e este mesmo grupo coletou um conjunto significativo de doações para compor o acervo inicial da mesma. Esta "geladeiroteca" fica aberta e os "trecheiros" podem retirar e incluir os materiais que desejassem, inclusive, podem assumir a "Classificação" do acervo conforme seus interesses. A "geladeiroteca" foi levada para Casa de Passagem no dia 07 de dezembro de 2015 e nesta ocasião foi feito um Sarau de lançamento junto as pessoais em situação de rua que estavam na Casa. Essa geladeira tem sido alimentada semestralmente pelo Grupo PET /BCl a partir de doações. Nesta ação houve participação direta de bibliotecário, autor desta pesquisa, tanto para a seleção prévia dos materiais considerando o contexto de usos possíveis das pessoas em situação de rua, como para sensibilizar os trecheiros na consulta e na leitura dos materiais que estavam ali disponíveis, sempre enfatizando que os livros poderiam ser levado junto com eles (livros trecheiros).

Outra atividade de destaque em que houve participação direta do Bibliotecário, autor deste trabalho, enquanto pesquisador e cidadão, foi junto ao Fórum da População em Situação de Rua. Este Fórum, articulado também pela Coordenação do Projeto Memória Falada, foi uma iniciativa de um projeto de extensão da Universidade Federal de São Carlos realizado no Paço Municipal da Prefeitura nos dias 26 e 27 de novembro de 2015, para aprovar o Fórum Permanente da População em Situação de Rua, contando assim com a parceria de vários apoiadores, deixando o caráter de projeto de extensão. 0 primeiro encontro foi no dia 15 de fevereiro de 2016, na Defensoria Pública, com a participação dos apoiadores numa rede interdisciplinar de atuações. Desde então a periodicidade do Fórum é mensal; o local a se reunir são as praças públicas com rotatividade das mesmas. A duração do encontro é de 
uma hora e meia a duas horas, começando às 9 horas e terminando às 11 horas. As discussões do Fórum são sempre em favor do coletivo (população em situação de rua), e foram levantadas por essa população muitas dúvidas com relação ao funcionamento e da política de acolhimento da Casa de Passagem. Discutiu-se a divulgação do fórum, e todos entenderam que todos devem assumir o papel de disseminadores das informações.

Uma das atividades importantes do Fórum foi a elaboração da carta proposta à todos os candidatos que concorreram a prefeitura. Elaborou-se uma carta com a Política Pública para a População em Situação de Rua em São Carlos, bem como, o convite para que todos participassem do Fórum, contamos com a participação dos candidatos e assinatura dessa carta, somente um não compareceu. Isso foi de extrema importância desse engajamento e um passo importante na construção de cidadania, e de que ações como essa deve pautar a vida dessas pessoas como cidadão com direitos e deveres.

\section{CONSIDERAÇÕES FINAIS}

No decorrer desse trabalho, com as atividades desenvolvidas via Projeto Memória Falada, na Casa de Passagem e no Fórum da População em Situação de Rua, pela observação participativa, foi possível perceber que o bibliotecário tem que ter uma visão macro da sociedade e de como se configuram os problemas sociais que porventura se desdobram na ausência de leitores e das práticas de leitura.

Trabalhar e pesquisas nestes ambientes socialmente sensíveis é ao mesmo tempo um processo de construção coletiva do conhecimento, é uma troca de saberes, é a articulação da teoria e prática, é o cuidado em falar e transmitir um conhecimento sem pretensão de ser maior que seu usuário, é a valorização das experiências acumuladas, e criar o vínculo de confiança entre o profissional e o usuário, é criar esse elo, onde sua informação, seu conhecimento vai garantir à ele a informação confiável, é a leitura do mundo que cada um carrega dentro de si como Paulo Freire cita, é essa leitura de 
cada um que tem que ser respeitada e compartilhada para garantir à essas pessoas a construção de sua autonomia.

Outro papel importante na atuação do bibliotecário é o de mediação entre usuário e o poder público. Temos habilidades que nos foram conferidas no decorrer do curso de graduação de coletar, organizar e disseminar a informação, portanto conseguimos pesquisar leis, normas, diretrizes, e conseguimos traduzir, levar o acesso dessas informações decodificando-as numa linguagem simples para fornecer à eles, transformando assim informação em conhecimento e passando pra eles, portanto uma forma de participação como mediador/educador é a participação em fóruns, ONGs, comunidades carentes, asilos, presídios, hospitais.

A mediação da leitura nesse contexto junto a população em situação de rua, é colocar toda práxis bibliotecária em ação, é conversar com seu usuário, é conhecê-lo, saber do que ele gosta, que assunto que interessa à ele, e como a informação pode ser sinônimo de acesso a cidadania.

Acredita-se que há de se pensar em mudanças na práxis e na postura profissional dos bibliotecários, bem como uma mudança no conceito das bibliotecas públicas, uma vez que se entende que estas devem ser espaços abertos de interação, de aceitação de todos os públicos, deve ser uma prestadora de serviços estes serviços humanizados e democráticos, contribuindo assim para o crescimento coletivo e sendo também um agente de transformação social, atendendo também a população em situação de rua, provendo-os de fontes e de informação que colaborem coma sua construção individual e coletiva enquanto cidadão críticos em relação aos seus direitos e deveres.

\section{REFERÊNCIAS}

ALMEIDA JÚNIOR, O. F. de; BORTOLIN, S. Mediação da informação e a leitura. 2007. In: Seminário em Ciência da Informação (SECIN), 2, 2007. Anais eletrônicos...Londrina: UEL, 2007. Disponível em:

<http://eprints.rclis.org/13269/1/MEDIAÇÃO_DA_INFORMAÇÃO_E_DA_LEITU RA.pdf>. Acesso em: 21 jun. 2016. 
BRASIL. Constituição (1988). Constituição da República Federativa do Brasil. 25. ed. Câmara dos Deputados, Coordenação de Publicações, 2005.

BRASIL. Presidência da República. Decreto $n^{\circ} 7.053$, de 23 de dezembro de 2009. Institui a Política Nacional para a População em Situação de Rua e seu Comitê Intersetorial de Acompanhamento e Monitoramento, e dá outras providências. Diário Oficial da União, Brasília, 24 dez. 2009. Disponível em: $<$ http://www.planalto.gov.br/ccivil_03/_Ato2007-

2010/2009/Decreto/D7053.htm>. Acesso em: 10 jun. 2016.

BRASIL. GOVERNO FEDERAL. Centro de Referência Especializado para População em Situação de Rua (Centro POP). Disponível em:

$<$ http://www.brasil.gov.br/observatoriocrack/cuidado/centro-pop.html>. Acesso em: 13 jan. 2016.

. Política nacional para inclusão social da população em situação de rua. Brasília. 2008. Disponível em: $<$ http://www.mpsp.mp.br/portal/page/portal/cao_civel/acoes_afirmativas/Pol.Nac ional-Morad.Rua.pdf>. Acesso em: 23 nov. 2016.

BRASIL. Ministério do Desenvolvimento Social e Combate à Fome. Relatório do I Encontro Nacional sobre População em Situação de Rua. Brasília: Secretaria Nacional de Assistência Social, 2006. 96 p. Disponível em: $<$ http://docplayer.com.br/3159793-Relatorio-do-i-encontro-nacional-sobrepopulacao-em-situacao-de-rua.html>. Acesso em: 12 dez. 2015.

FREIRE, Paulo. A Importância do Ato de Ler: em três artigos que se completam. 51. ed. São Paulo: Cortez, 2011.

MARQUES NETO, J. C. (Org.). Plano Nacional do Livro e da Leitura: textos e história. São Paulo: Cultura Acadêmica Editora, 2006. 340p.

MEMÓRIA FALADA, Wordpress, 2016. Disponível em: $<$ https://memoriafalada.wordpress.com/2016/10/19/varal/>. Acesso em: 06 jun. 2018.

MEMÓRIA FALADA UFSCar. YouTube, 2016. Disponível em: $<$ https://www.youtube.com/watch?v=LMcDrL1tELI\&feature=youtu.be $>$. Acesso em: 06 jun. 2018.

ORGANIZAÇÃO DAS NAÇÕES UNIDAS (ONU). BRASIL. A história da Organização. Disponível em: <https://nacoesunidas.org/conheca/historia>. Acesso em: 10 jun. 2016.

ORGANIZAÇÃO DAS NAÇÕES UNIDAS (ONU). BRASIL. Declaração Universal dos Direitos Humanos: O que são os direitos Humanos?. Brasil. Disponível em: <http://www.dudh.org.br/definicao>. Aceso em: 10 jun. 2016. 
ORGANIZAÇÃO DAS NAÇÕES UNIDAS (ONU). BRASIL. RIO DE JANEIRO. Centro de Informação das Nações Unidas Rio de Janeiro: Conheça a ONU. Disponível em: <http://unicrio.org.br/conheca-a-onu>. Acesso em: 10 jun. 2016.

ORGANIZAÇÃO DAS NAÇÕES UNIDAS (ONU). BRASIL. UNESCO:

Organização das Nações Unidas para a Educação, a Ciência e a Cultura. Disponível em: <https://nacoesunidas.org/agencia/unesco>. Acesso em: 10 jun.2016.

ORGANIZAÇÃO DAS NAÇÕES UNIDAS (ONU). Declaração Universal dos Direitos do Homem das Nações Unidas. Estados Unidos, 1945. Disponível em: $<$ http://www.youthforhumanrights.org/pt/what-are-human-rights/universaldeclaration-of-human-rights/introduction.html>. Acesso em: 10 jun. 2016.

ORGANIZAÇÃO DAS NAÇÕES UNIDAS PARA A EDUCAÇÃO, A CIÊNCIA E A CULTURA (UNESCO). Representação da UNESCO no Brasil: Educação para todos. Disponível em:

<http://www.unesco.org/new/pt/brasilia/education/education-for-all/>. Acesso em: 10 jun. 2016.

ORGANIZAÇÃO DAS NAÇÕES UNIDAS PARA A EDUCAÇÃO, A CIÊNCIA E A CULTURA (UNESCO). Segundo relatório global sobre aprendizagem e educação de adultos. Brasília: UNESCO, 2014. Disponível em:

$<$ http://unesdoc.unesco.org/images/0023/002307/230725por.pdf >. Acesso em: 21 jun. 2016.

SANTOS, C. M. dos; SANTOS, P. S. S. dos; ASSUNÇÃO, S. S. Ética, cidadania e o profissional da informação: responsabilidades e competência informacional. In: Encontro Regional dos Estudantes de Biblioteconomia, Documentação, Ciência e Gestão da informação (EREBD), 17, 2014. Anais eletrônicos... Fortaleza: Universidade Federal do Ceará, 2014. p. 1 - 9. Disponível em: <http://www.erebdfortaleza2014.ufc.br/gt/GT3/ÉTICA, CIDADANIA E O PROFISSIONAL DA INFORMAÇÃO. responsabilidades e competência informacional.pdf>. Acesso em: 12 jan. 2016.

SILVA, C. R. et al. Memória falada: do registro ao acesso às memórias da pessoa em situação de rua. In: Semana de Estudos em Terapia Ocupacional da UFSCar, 2017. Anais... São Carlos: UFSCar, 2017. p. 169-172.

\section{THE LIBRARIAN'S ACTIVITIES TOWARD THE HOMELESS POPULATION}

\section{ABSTRACT}

Introduction: Many rights are denied to people who live on the streets in Brazil, among them, the right of access to books and reading. Objectives: It was the objective of this research to discuss the place of the Librarian as promoter and participant in actions of promotion and access to books and reading for people in this situation. 
Methodology: This is an exploratory research, based on bibliographical and documentary research and participant observation in an extension project entitled "Spoken memory" developed by the Federal University of São Carlos, together with Casa de Passagem in the municipality of São Carlos. Results: The results point to a need for a more critical education to be offered to the professional librarian so that they can be sensitized and act in a political way with issues that involve society. Conclusion: It also demonstrates, into practice, how it is possible for the Librarian to work with public sectors for the development of social projects.

Descriptors: Librarian. People who live on the streets. Society.

\title{
LAS ACTIVIDADES DEL BIBLIOTECARIO JUNTO A LA POBLACIÓN SIN HOGAR
}

\begin{abstract}
RESUMEN
Introducción: Muchos derechos son renegados a las personas que viven en las calles en Brasil, entre ellos, el derecho de acceso a los libros y la lectura. Objetivo: Fue objetivo de esta investigación discutir el lugar del bibliotecario como promotor y participante en acciones de promoción y acceso a libros y lectura para personas en esta situación. Metodologia: Se trata de una investigación exploratoria, con base en la investigación bibliográfica y documental y la observación participante en proyecto de extensión titulado "Memoria hablada" desarrollado por la Universidad Federal de São Carlos, junto a la Casa de Passagem del municipio de São Carlos. Resultados: Los resultados apuntan a la necesidad de ofrecer una educación más crítica al profesional bibliotecario para que pueda sensibilizarse y actuar de forma política con cuestiones que involucran a la sociedad. Conclusión: Demuestra cómo es posible, en la práctica, que el Bibliotecario trabaje junto a sectores públicos para el desarrollo de proyectos sociales
\end{abstract}

Descriptores: Bibliotecario. Personas que viven en las calles. Sociedad.

Recebido: 04.03.2018

Aceito: 31.05 .2018 